\title{
PRÁTICAS PROFISSIONAIS EM CIÊNCIA DA INFORMAÇÃO: UMA REVISÃO NA LITERATURA BRASILEIRA ${ }^{1}$
}

\author{
Jorge Santa Anna \\ Mestrando no PPG em Gestão e Organização do Conhecimento - UFMG \\ jorjao20@yahoo.com.br \\ Élida Mara Mascarenhas Pieri \\ Mestranda no PPG em Gestão e Organização do Conhecimento - UFMG \\ elidapieri@gmail.com
}

\section{Resumo}

Tematiza a Ciência da Informação e suas relações com o profissionalismo. Objetiva apresentar práticas profissionais advindas da Ciência da informação e sua contribuição com as profissões da informação. Além disso, a pesquisa explora conceitos e características principais inerentes à área da Ciência da Informação. Os procedimentos metodológicos pautaram-se em revisão de literatura em artigos publicados em periódicos do âmbito profissional. Após análise e discussão, tendo 31 artigos selecionados para revisão, constatou-se que a Ciência da Informação fomenta inúmeras práticas profissionais, tais como: fazeres técnicos, voltados à produção, tratamento e armazenamento; ampliação do ciclo informacional, a qual se estende à questão da disseminação, do acesso e do uso da informação; práticas de comunicabilidade, interatividade e recuperação da informação; práticas de gestão da informação e seus fluxos; trabalho interdisciplinar em meio à atuação autônoma, inovadora e audaciosa; ações a favor do usuário, conhecendo seu perfil, necessidades, limitações e seu comportamento; prestação de atendimento personalizado e qualificado; e, por fim, ações de inclusão social, por meio de práticas interventivas, as quais viabilizem a construção da cidadania, desencadeando uma sociedade mais inclusiva, democrática e igualitária. Essas práticas demonstram a concepção técnica e humanista inerentes à Ciência da Informação, por conseguinte, caracteriza esse campo do conhecimento como uma área social em prol da adequação do fator humano, enquanto principal elemento do contexto social.

Palavras-chave: Tecnologias de Informação e Comunicação. Acesso e uso à informação. Ciência da Informação. Práticas profissionais em Ciência da Informação.

\section{INTRODUÇÃO}

As necessidades sociais constituem o ponto de partida para a formação $\mathrm{e}$ desenvolvimento de práticas profissionais. Tais práticas estão emaranhadas a um corpus teórico, metodológico e pragmático, o qual sustenta a consolidação de uma profissão, formada por agentes envolvidos a favor de uma ou mais causas, tendo em vista, promover a resolução de problemas inseridos em um contexto hamano-social.

Ora, as sociedades humanas estão em constantes transformações, o que ocasiona às profissões uma frequente dinamicidade quanto às formas de atuação. Essas formas devem ser pautadas em descobertas, tendo em vista provocar a evolução do conhecimento científico, tornando-o capaz de solucionar problemas inerentes às relações sociais. Portanto, há uma intensa relação, de complementaridade, entre profissão e ciência.

As profissões, em grande parte, constituem produtos oriundos com as descobertas científicas, estando ambas relacionadas ao aperfeiçoamento do conhecimento, de modo a provocar melhores condições de vida às sociedades. A diferença entre essas duas entidades diz respeito, grosso modo, ao reconhecimento legal instituído no sistema

\section{(cc) EY-NC}


normativo das sociedades acerca dos trabalhos desenvolvidos: enquanto a ciência para existir não precisa de regulamentação para exercício profissional, as profissões, por sua vez, precisam estar legalmente reconhecidas pelos órgãos controladores que regulamentam as leis trabalhistas.

As ciências para se consolidarem precisam, tão somente, de possuir um conjunto de agentes que comungam interesses de investigação similares e que, através de métodos específicos, promovem descobertas, objetivando solucionar problemáticas. $\mathrm{O}$ fazer científico constitui um conjunto de atividades de pesquisa, sendo essas fundamentadas em métodos lógicos e consistentes, devidamente aprovados por especialistas, os quais garantirão legitimidade aos resultados obtidos e divulgados (MUELLER, 2003).

As profissões, por sua vez, embora estejam irmanadas ao fazer científico, diferese por estarem sustentadas em uma jurisdição. Segundo Abbott (1998), essa jurisdição inerente a cada tipo de profissão constitui sua garantia de reconhecimento no sistema social e, dessa forma, permitirá que cada profissão estabeleça seu monopólio em atividades específicas a serem realizadas junto à sociedade.

No entendimento de Cunha (2006, p. 146), essa jurisdição apontada por Abbott (1998) representa uma forma estratégica de controle estabelecida pelos órgãos defensores da profissão. Além disso, esse controle é determinado, em grande parte, pelo domínio das abstrações que geram a prática profissional. Portanto, quanto maior a capacidade de abstração teórica de uma profissão, mais sólida ela será no sistema social e profissional. Assim, "[...] a habilidade das profissões em manter sua jurisdição ou seu espaço resulta, dessa forma, em parte, do prestígio do seu sistema de conhecimento". Cunha (2006) discorre ainda que cada profissão se relaciona com a sociedade através de um contrato implícito, o qual the garante o direito exclusivo do exercício profissional, que, por sua vez, proporciona à sociedade, segurança na qualidade $\mathrm{e}$ eficiência dos produtos e serviços oferecidos.

Cunha (2006), analisando diversas teorias acerca da profissionalização, ensina que as profissões estão em constante desenvolvimento, com o intuito de adequar-se às tendências sociais. Portanto, os campos profissionais adentram-se em um dinamismo frequente, de modo que enquanto umas profissões desaparecem, outras surgem e ainda algumas são reformuladas, considerando os novos desafios existentes na sociedade.

Mueller (2004), ao discorrer sobre o processo evolutivo da Ciência da Informação e o papel dos profissionais da informação na sociedade moderna, recorre à teoria de Abbott (1988) e esclarece que as profissões, de uma forma em geral, estão inseridas em um contexto de competitividade, havendo disputa de poder entre os diversos campos profissionais. Assim, a profissionalização acontece em meio à busca por argumentos que justifiquem a sua aceitação e reconhecimento na sociedade, permeado por um processo ideológico e rival (MUELLER, 2004).

Salienta-se que o aspecto inter, trans e multidisciplinar de uma profissão pode acarretar à fusão entre determinadas profissões, como também pode estabelecer os limites de atuação de cada campo, sendo esses instituídos e reconhecidos por meio da jurisdição específica de cada campo (MUELLER, 2004).

No caso da Ciência da Informação, sobretudo no âmbito de Brasil, a falta de delimitação (limites) no que se refere ao relacionamento com outras áreas da informação acarreta à Ciência da Informação sua ampla abrangência, por conseguinte, ocasiona dificuldades de consolidação como profissão consolidada como acontece com a Biblioteconomia, Arquivologia e Museologia, por exemplo (ARAÚJO, 2014).

Assim, a Ciência da Informação manifesta-se, na prática, como uma grande área, a qual viabiliza conhecimento teórico e prático para as demais profissões que lidam com a informação e que, tradicionalmente, possuem corpus profissional e jurisdição devidamente reconhecidas e instituídas legalmente (ARAÚJO, 2014).

Importante considerar que a Ciência da Informação representa uma ciência moderna e em desenvolvimento, oriunda principalmente 
do avanço tecnológico, das novas formas de se tratar e disseminar informação e das preocupações com o uso dessa informação (ARAÚJO, 2014). Com os avanços conquistados pela Biblioteconomia, nas últimas décadas, diversas teorias propostas pela Ciência da Informação foram absorvidas pela Biblioteconomia, acarretando novas práticas bibliotecárias, as quais foram sentidas, principalmente, através da formação profissional oferecida pelas escolas de Biblioteconomia do Brasil (SOUZA, 2006).

Com efeito, entende-se que a Ciência da Informação manifesta-se como um campo complementar às práticas profissionais de áreas da informação, principalmente quanto à Biblioteconomia, Arquivologia e Museologia (SMIT, 2000), pelo menos no contexto brasileiro. Esse fato, talvez, seja o motivo que justifica as dificuldades em profissionalizar a Ciência da Informação, sendo ela uma área incorporada, principalmente, à Biblioteconomia, conforme demonstra a Classificação Brasileira de Ocupações, ao categorizar os bibliotecários como profissionais da informação (BRASIL, CBO, 2002).

Portanto, os bibliotecários são profissionais da informação, tendo suas práticas ampliadas a partir da contribuição advinda da Ciência da Informação. Para Ribas e Ziviani (2007), esses profissionais usufruem de um conjunto de práticas profissionais amplas que requer uma atuação cada vez mais difusa, contemplando diferentes instâncias e contextos, relacionando-se com diferentes profissionais, na busca pelo tratamento, armazenamento, recuperação e uso da informação, em prol de uma sociedade mais inclusiva.

Entende-se, aqui, que a Ciência da Informação viabiliza práticas a serem exercidas por profissões a ela relacionadas, principalmente, quanto ao fazer bibliotecário. No entanto, outros profissionais também são beneficiados com as propostas teóricas e metodológicas advindas da Ciência da Informação, tais como os museólogos, documentalistas e jornalistas (LE COADIC, 2004).

Nesse enfoque, entende-se que no contexto brasileiro, segundo Barbosa (1998), a legislação que regulamenta o exercício profissional dos profissionais da informação não se encontra em sintonia com as novas realidades com as quais se deparam esses profissionais multifacetados. Observam-se, com grande frequiência, práticas diferenciadas e a concretização de ambientes transprofissionais.

Todavia, mesmo havendo desvios e incoerências no universo da profissionalização, o que se sabe é que a Ciência da Informação tem contribuído com a produção de conhecimento, haja vista resolver problemas inerentes ao crescimento da informação na sociedade. Sua característica metodológica e epistemológica tem proporcionado avanços ao viabilizar práticas profissionais inovadoras (ARAÚJO, 2010).

Assim sendo, alguns questionamentos surgem: o que caracteriza a Ciência da Informação como área de conhecimento? Que práticas profissionais são geradas a partir dos estudos em Ciência da Informação? Que campos profissionais são mais contemplados com essas práticas?

Logo, este texto objetiva apresentar práticas profissionais advindas da Ciência da informação e sua contribuição com as profissões da informação. Além disso, a pesquisa explora conceitos e características principais inerentes à área da Ciência da Informação. Metodologicamente, utilizou-se revisão de literatura em artigos publicados nos últimos anos em revistas científicas brasileiras, que abordem a temática em apreço, de modo a refletir sobre as práticas profissionais promovidas pela Ciência da Informação e que são discorridas na literatura brasileira.

\section{ALGUMAS CARACTERÍSTICAS E CONCEITOS INERENTES À CIÊNCIA DA INFORMAÇÃO}

A Ciência da Informação caracteriza-se, em um primeiro momento, como uma ciência cujo objeto de estudo está pautado na informação, seja ela manifestada em diferentes formas documentais e disseminada em diversos canais de comunicação, atuando como insumo básico para fomentar estratégias para produção de conhecimento, resolução de 
problemas e formulação de estratégias (VALENTIM, 2002).

Sendo assim, a informação, na sociedade atual, assume diferentes funções e características, refletindo o contexto em que é produzida e gerenciada. Portanto, fala-se em informação tecnológica, informação industrial, informação científica, dentre tantas outras abordagens e nomenclaturas (MCGARRY, 1999).

Devido a essa importância e abrangência que a informação assume a cada dia, é preciso reformular as técnicas de tratamento, armazenamento e disseminação, haja vista, não apenas adentrar-se ao suporte tecnológico que registra a informação, mas também é preciso entender um conjunto de forças, de condições e elementos que perfazem o contexto informacional. Portanto, é com essa desvinculação da informação ao suporte e sua dinamicidade em diferentes contextos que a Ciência da Informação ganha espaço para se desenvolver (BORKO, 1968).

Assim, resumidamente, considera-se que

\begin{abstract}
A Ciência da Informação, nascida formalmente em 1962, em uma reunião do Georgia Institute of Technology, é uma área científica, com identidade e unidade na perspectiva epistemológica e que abrange componentes aplicados tais como a Biblioteconomia, a Arquivologia, a Gestão da Informação e os Sistemas Tecnológicos de Informação, todas elas centradas sobre um mesmo objeto de estudo e de trabalho - a Informação $\quad-, \quad$ contextualizado em diferentes ambiências e serviços (ARAÚJO, 2010, p. 82, grifo nosso).
\end{abstract}

A história evolutiva das profissões e ciências que lidam com a informação fornece uma acepção acerca das influências que as transformações sociais e tecnológicas, assim como a mudança no conceito de arquivo, biblioteca e museu - os quais deixam de serem considerados, tão somente, como entidades custodiadoras de documentos proporcionam uma compreensão na ampliação de problemas, o que fez nascer uma nova ciência, chamada de Ciência da Informação (ARAÚJO, 2014).

Assim, percebe-se que o nascimento dessa ciência está ligado ao desenvolvimento de algumas áreas como a Bibliografia, a Biblioteconomia e Documentação. Por isso, constata-se um certo a-historicismo no que se refere à trajetória evolutiva da Ciência da Informação. Tal área está imbricada ao desenvolvimento tecnológico vivenciado no período da Segunda Guerra Mundial, atreladas à evolução dos recursos e canais de comunicação (RUSSO, 2010).

Concomitante a esses acontecimentos, a evolução dos sistemas informatizados voltados não apenas mais para armazenar a informação, mas, principalmente, para disseminá-la, traz à tona um novo olhar ao processo de recuperação da informação, logo, viabiliza novas práticas a serem realizadas no ambiente digital, tendo em vista tornar a informação mais acessível (RUSSO, 2010).

Em Araújo (2014), tem-se que, além das transformações vivenciadas nas áreas da informação, contextualizadas aos acontecimentos históricos e revolucionários dos séculos XIX e XX, deve-se considerar, também, uma nova preocupação surgida, em que representou uma reviravolta em todas as profissões, a preocupação com o uso da informação, por conseguinte, a valorização que é atribuída ao usuário ou cliente dos serviços e produtos oferecidos na sociedade.

Desse modo, despontaram-se dois grandes acontecimentos, que, em linhas gerais, podem ter sido o alicerce para a gênese e expansão da Ciência da Informação: o novo conceito de documento e a preocupação com o uso da informação. Tais acontecimentos estão associados ao aparecimento da Documentação, sendo que novas técnicas foram desenvolvidas a fim de permitir maior acessibilidade aos documentos existentes nos acervos documentários.

Nesse enfoque, a Ciência da Informação tem em seu bojo central,

[...] Em primeiro lugar, uma preocupação não com a custódia, a posse dos documentos, mas com a sua circulação e sua disseminação da maneira mais produtiva possível. Depois, o foco não propriamente nos documentos (registro físico), mas em seu conteúdo objetivo ou, dito de outro modo, na informação contida nos documentos (ARAÚJO, 2014, p. 111). 
A mudança de paradigma do documento para a informação, bem como a preocupação com o uso da informação foram questões que não estavam inseridas nas propostas até então defendidas pelas disciplinas da informação. A Ciência da Informação configura-se como uma disciplina científica, cujo objetivo é produzir produtos e serviços a fim de garantir o acesso e a utilização da informação, no intuito dela acarretar conhecimentos, competências e inovação, atendendo necessidades específicas e das mais variadas (RUSSO, 2010).

Ora, entende-se que a preocupação e estudo da informação constituem uma das principais características que identificam e demarcam o campo estendido à Ciência da Informação. Além dessa característica, somam-se outras duas, que são: a interdisciplinaridade e a sua relação com a tecnologia da informação e comunicação (SARACEVIC, 1996).

No que se refere à interdisciplinaridade, o autor supracitado acredita que tal área do conhecimento é interdisciplinar por natureza, embora suas relações com outras disciplinas estejam mudando. A evolução interdisciplinar está longe de ser completada. No que diz respeito ao avanço tecnológico, considera-se que essa ciência está inexoravelmente ligada à tecnologia da informação. O imperativo tecnológico determina a Ciência da Informação, como ocorre também em outros campos. Em sentido amplo, o imperativo tecnológico está impondo a transformação da sociedade moderna em sociedade da informação, era da informação ou sociedade pós-industrial (SARACEVIC, 1996).

Considera-se, ainda, outrossim, que a Ciência a Informação também se caracteriza e se destaca por contribuir com a evolução das sociedade, apresentando-se, nesse contexto, como uma disciplina humana, tendo, por sua vez, o importante papel a desempenhar por sua forte dimensão social e humana, que ultrapassa a tecnologia. Essas características ou razões constituem o modelo para compreensão do passado, presente e futuro da Ciência da Informação e dos problemas e questões que ela enfrenta (SARACEVIC, 1996).
Com efeito, considerando as questões discorridas por Saracevic (1996) a respeito das características da Ciência da Informação e sua relação com as transformações sociais, sobretudo na ampliação da informação na sociedade, reflete-se que

[...] foi a convergência dessas questões que possibilitou à Ciência da Informação ampliar seu quadro de compreensão para além da dimensão física e quantitativa da informação. A Ciência da Informação não nasceu como uma ciência tipicamente social, mas identificou-se ao longo dos anos com o escopo das ciências sociais à medida que se orientou para uma postura em que os sujeitos passaram a ser vistos como o principal ator e objetivos dos chamados sistemas de informação, e que métodos e conceitos das ciências humanas e sociais foram aplicados para o seu estudo (ARAÚJO, 2014, p. 122, grifo nosso).

Consequentemente ao avanço tecnológico, novas técnicas de representação da informação, tendo em vista a recuperação da informação, foram geradas, havendo a necessidade de constante gestão dos sistemas informatizados que funcionam como verdadeiros mediadores na busca da informação, mas que requer a intervenção humana para que esse processo se consolidasse de forma efetiva (ALVES et al., 2007).

A Ciência da Informação, portanto, relaciona-se com a recuperação da informação, estando ligada à Ciência da Computação. Nesse enfoque, sua conceituação pode ser definida como a área do conhecimento que desenvolve métodos, técnicas, ferramentas e instrumentos de trabalho no intuito de viabilizar a geração, organização, processamento, recuperação e o uso da informação em diferentes canais e ambientes de comunicação (ALVES et al., 2007).

Ora, devido a sua característica relacional com outras disciplinas, ciências e profissões, constata-se seu caráter inter, trans e multidisciplinar. Logo, a Ciência da Informação constitui, na prática, uma ciência ou área do conhecimento que viabiliza subsídios para auxiliar as práticas 
profissionais exercidas em diversas profissões, sobretudo em profissões tradicionais, o que viabiliza a necessidade de reformulação no processo de formação profissional (FROEHLICH, 2009).

Em virtude dessas caracterizações e conceitos inerentes à Ciência da Informação e seu aspecto epistemológico e científico como se apresenta no Brasil, além da falta de jurisdição a ela atribuída, presume-se que os resultados oriundos das investigações dessa ciência diluem-se em meio às diferentes práticas profissionais, de diferentes campos do saber. Portanto, discorrer acerca das práticas profissionais viabilizadas por essa ciência e sua contribuição com a profissionalização será objeto de análise da revisão de literatura realizada na seção seguinte.

\section{PROCEDIMENTOS METODOLÓGICOS}

Este estudo está alicerçado em uma revisão sistemática da literatura publicada no Brasil, cujo tema seja Ciência da Informação e profissionalismo. De modo geral, esta modalidade de metodologia tem a proposta de realizar um levantamento ou mapeamento teórico, tendo em vista detectar debates e contribuições sobre um determinado tema pesquisado (ECHER, 2001).

Portanto, o estudo mapeia o que vem sendo publicado na literatura brasileira, por meio de artigos científicos, que contemplem a temática deste estudo. Através do levantamento realizado, disponibilizaram-se os documentos encontrados de forma esquematizada em um quadro, para, posteriormente, realizar as análises do conteúdo de cada publicação, a fim de encontrar reflexões acerca do objeto deste trabalho que é "as práticas profissionais em Ciência da Informação".

Optou-se em investigar os artigos publicados, apenas, nos periódicos indexados na base de dados referencial de artigos de periódicos em Ciência da Informação (BRAPCI), sendo selecionados, tão somente, os periódicos que publicam, preferencialmente, textos oriundos de atividades profissionais. Sendo assim, recorreu-se a periódicos gerenciados por associações profissionais, como a Revista Brasileira de Biblioteconomia e Documentação (RBBD) e a Revista ACB. Recorreu-se, também, a um terceiro periódico, qual seja, Revista Biblionline, gerenciada por um curso universitário ${ }^{1}$. A escolha desses periódicos deveu-se ao fato de eles priorizarem trabalhos relacionados ao âmbito da prática profissional.

Após escolha dos periódicos, recorreu-se aos processos de busca e recuperação dos trabalhos, sendo esse processo realizado no catálogo eletrônico dos referidos periódicos. Após recuperação, os artigos foram analisados a fim de serem selecionados, caso abordassem aspectos relacionados à temática de pesquisa. Ao final, a amostra foi apresentada em forma de quadro.

\subsection{REVISÃO DE LITERATURA}

Os descritores utilizados para busca e recuperação dos artigos no catálogo desses periódicos foram os seguintes: "Ciência da Informação" e "Profissional da informação". Através da busca-se, obtiveram-se os dados constantes no quadro 1 , a seguir:

\footnotetext{
${ }^{1}$ Esclarece-se, aqui, que a RBBD é gerenciada pela Federação Brasileira de Bibliotecários, Cientistas da Informação e Instituições (FEBAB); a revista $\mathrm{ACB}$ pela Associação Catarinense de Bibliotecários e a Biblionline é gerenciada pelo Departamento de Ciência da Informação da Universidade Federal da Paraíba. No que se refere à última avaliação da Comissão de Aperfeiçoamento de Pessoal de Nível Superior (CAPES), realizada um ano anterior à elaboração deste artigo (em 2015), essas revistas possuíam as seguintes atribuições avaliativas: B1, B2 e B1, respectivamente.
} 
Quadro 1 - Processo de busca, recuperação e seleção de artigos a compor a amostra de pesquisa

\begin{tabular}{|c|c|c|c|c|c|}
\hline Periódico & $\begin{array}{l}\text { Descritor } \\
\text { utilizado }\end{array}$ & $\begin{array}{c}\text { Itens } \\
\text { recuperados }\end{array}$ & $\begin{array}{c}\text { Itens } \\
\text { Selecionados }\end{array}$ & $\begin{array}{c}\text { Itens } \\
\text { selecionados } \\
\text { por } \\
\text { periódico }\end{array}$ & $\begin{array}{l}\text { Total da } \\
\text { amostra }\end{array}$ \\
\hline \multirow[t]{2}{*}{ Revista ACB } & $\begin{array}{l}\text { Ciência da } \\
\text { informação }\end{array}$ & 28 & 4 & \multirow[b]{2}{*}{7} & \multirow{6}{*}{31} \\
\hline & $\begin{array}{c}\text { Profissional da } \\
\text { informação }\end{array}$ & 13 & 3 & & \\
\hline \multirow{2}{*}{$\begin{array}{c}\text { Revista } \\
\text { Biblioteconomia e } \\
\text { Documentação }\end{array}$} & $\begin{array}{l}\text { Ciência da } \\
\text { informação }\end{array}$ & 26 & 6 & \multirow[b]{2}{*}{16} & \\
\hline & $\begin{array}{l}\text { Profissional da } \\
\text { informação }\end{array}$ & 39 & 10 & & \\
\hline \multirow[t]{2}{*}{ Revista Biblionline } & $\begin{array}{l}\text { Ciência da } \\
\text { informação }\end{array}$ & 18 & 4 & \multirow[b]{2}{*}{8} & \\
\hline & $\begin{array}{c}\text { Profissional da } \\
\text { informação }\end{array}$ & 11 & 4 & & \\
\hline
\end{tabular}

Fonte: o autor (2016).

Importante discorrer que, a seleção dos artigos foi realizada por meio do processo de análise do título, do resumo e das palavraschave de cada item recuperado. Os artigos selecionados foram, apenas, aqueles que possuíam os descritores presentes nas referidas partes dos artigos. Além desses critérios, recorreu-se à leitura do resumo, da introdução e conclusão de cada artigo, mesmo que esses não possuíssem os respectivos descritores. Dessa forma, garantiu-se uma amostra mais consistente quanto ao assunto central investigado.

A fim de tornar mais ilustrativo, apresentase, por meio do quadro 2, a sistematização dos 31 artigos selecionados, contento alguns dados como: nome do periódico, autor, título e data da publicação. Os artigos estão separados por periódicos, sendo alocados em ordem crescente por ano de publicação.

Quadro 2 - Demonstrativo da amostragem de pesquisa - 31 artigos selecionados

\begin{tabular}{|c|c|c|c|}
\hline PERIÓDICO & AUTOR (ES) & TÍTULO & $\begin{array}{l}\text { ANO } \\
\text { PUBLIC } \\
\text { AÇÃO }\end{array}$ \\
\hline \multirow{6}{*}{ Revista ACB } & $\begin{array}{l}\text { SOUZA, Francisco das } \\
\text { Chagas }\end{array}$ & $\begin{array}{c}\text { As diferentes práticas bibliotecárias } \\
\text { brasileiras e sua relação com o futuro da } \\
\text { educação profissional }\end{array}$ & 1996 \\
\hline & $\begin{array}{l}\text { OHIRA, Mria de Lourdes } \\
\text { Blatt; OLIVEIRA, Sueli } \\
\text { Ferreira Julio de }\end{array}$ & $\begin{array}{c}\text { Utilização de tecnologias de informação } \\
\text { pelas bibliotecas da área jurídica de } \\
\text { Florianópolis - SC }\end{array}$ & 1997 \\
\hline & $\begin{array}{c}\text { SOUZA, Francisco das } \\
\text { Chagas }\end{array}$ & $\begin{array}{l}\text { Interatividade comunicacional no terceiro } \\
\text { milênio }\end{array}$ & 1997 \\
\hline & $\begin{array}{l}\text { BLATTMANN, Úrsula; } \\
\text { RADOS, Gregório J. } \\
\text { Varvakis }\end{array}$ & $\begin{array}{l}\text { Bibliotecários na sociedade da } \\
\text { informação: mudança de rótulos, funções } \\
\text { ou habilidades? }\end{array}$ & 2000 \\
\hline & $\begin{array}{l}\text { CALDIN, Clarice } \\
\text { Fortkamp } \\
\end{array}$ & $\begin{array}{c}\text { Atuação do bibliotecário diante da } \\
\text { globalização da informação }\end{array}$ & 2011 \\
\hline & $\begin{array}{l}\text { CORRÊA, Elisa Cristina } \\
\text { Delfini; ZAMBAN, } \\
\text { Debora; OLIVEIRA, } \\
\text { Viviane Martins Arruda de }\end{array}$ & $\begin{array}{l}\text { Blogs sobre biblioteconomia e a } \\
\text { ressignificação da profissão no Brasil: } \\
\text { uma análise do blog bibliotecários sem } \\
\text { fronteiras }\end{array}$ & 2013 \\
\hline
\end{tabular}




\begin{tabular}{|c|c|c|c|}
\hline & $\begin{array}{l}\text { SANTA ANNA, Jorge; } \\
\text { PEREIRA, Gleice }\end{array}$ & $\begin{array}{l}\text { Ampliando o campo de atuação } \\
\text { bibliotecária: o bibliotecário como } \\
\text { consultor informacional }\end{array}$ & 2014 \\
\hline \multirow{16}{*}{$\begin{array}{c}\text { Revista } \\
\text { Brasileira de } \\
\text { Biblioteconomi } \\
\text { a e } \\
\text { Documentação }\end{array}$} & SCHWEITZER, Fernanda & $\begin{array}{l}\text { Os novos perfis dos profissionais da } \\
\text { informação nas bibliotecas universitárias }\end{array}$ & 2007 \\
\hline & $\begin{array}{c}\text { BARROS, Daniela Melaré } \\
\text { Vieir }\end{array}$ & $\begin{array}{l}\text { Ambientes mediatizados para a formação } \\
\text { continuada dos profissionais da } \\
\text { informação }\end{array}$ & 2007 \\
\hline & $\begin{array}{l}\text { CARVALHO, Kátia de; } \\
\text { REIS, Marivaldina Bulcão }\end{array}$ & $\begin{array}{c}\text { Missão do bibliotecário: a visão de José } \\
\text { Ortega y Gasset }\end{array}$ & 2007 \\
\hline & $\begin{array}{l}\text { ROCHA, Maria Meriane } \\
\text { Vieira; ARAÚJO, Eliany } \\
\text { Alvarenga de }\end{array}$ & $\begin{array}{l}\text { Educação continuada de profissionais da } \\
\text { informação: perfil da ação de } \\
\text { bibliotecários de instituições de ensino } \\
\text { superior privado no município de João } \\
\text { Pessoa - PB } \\
\end{array}$ & 2007 \\
\hline & $\begin{array}{c}\text { VAN DER LAAN, Regina } \\
\text { Helena; ALVORCEM, } \\
\text { Rochelle Martins } \\
\end{array}$ & $\begin{array}{l}\text { A terminologia expressa no discurso dos } \\
\text { especialistas da área da ciência da } \\
\text { informação: um estudo de caso }\end{array}$ & 2007 \\
\hline & $\begin{array}{l}\text { MOREIRA, Jonatan; } \\
\text { CARVALHO, José Oscar } \\
\text { Fontanini de } \\
\end{array}$ & $\begin{array}{c}\text { Estudo de métodos e técnicas da ciência } \\
\text { da informação aplicáveis à educação a } \\
\text { distância }\end{array}$ & 2008 \\
\hline & $\begin{array}{c}\text { BECKER, Caroline da } \\
\text { Rosa Ferreira; GROSCH, } \\
\text { Maria Selma } \\
\end{array}$ & $\begin{array}{l}\text { A formação do leitor através das } \\
\text { bibliotecas: o letramento e a ciência da } \\
\text { informação como pressupostos }\end{array}$ & 2008 \\
\hline & $\begin{array}{l}\text { FERNANDES, Marcia } \\
\text { Leite }\end{array}$ & $\begin{array}{c}\text { O cognitivismo na CI: a leitura de } \\
\text { Ingwersen e a passagem do modelo } \\
\text { matemático ao cognitivo }\end{array}$ & 2011 \\
\hline & $\begin{array}{l}\text { SANTOS JUNIOR, } \\
\text { Roberto Lopes }\end{array}$ & $\begin{array}{l}\text { Análise sobre o desenvolvimento do } \\
\text { campo de estudo em informação } \\
\text { científica e técnica nos Estados Unidos e } \\
\text { na antiga União Soviética durante a } \\
\text { guerra fria (1945-1991) }\end{array}$ & 2012 \\
\hline & $\begin{array}{l}\text { MEDEIROS, Jackson da } \\
\text { Silva }\end{array}$ & $\begin{array}{l}\text { Considerações sobre a informação na } \\
\text { terceira ordem da ordem: um olhar a } \\
\text { partir dos paradigmas da Ciência da } \\
\text { Informação }\end{array}$ & 2012 \\
\hline & $\begin{array}{l}\text { SIQUEIRA, Jessica } \\
\text { Camara }\end{array}$ & $\begin{array}{l}\text { Ciência da Informação: personagem da } \\
\text { pós-modernidade }\end{array}$ & 2012 \\
\hline & $\begin{array}{l}\text { ISHIKAWA, Maria Inês } \\
\text { Garcia; BELLUZZO, } \\
\text { Regina Célia Baptista } \\
\end{array}$ & $\begin{array}{l}\text { Práticas inclusivas para deficientes } \\
\text { visuais, baseadas na informação e } \\
\text { conhecimento: reflexões e ações }\end{array}$ & 2013 \\
\hline & $\begin{array}{c}\text { ALVES, Claudio Augusto; } \\
\text { DUARTE, Emeide } \\
\text { Nobrega } \\
\end{array}$ & $\begin{array}{c}\text { Cultura e informação: uma interface } \\
\text { complexa e definidora na vida das } \\
\text { organizações }\end{array}$ & 2014 \\
\hline & $\begin{array}{l}\text { TANUS, Gabrielle } \\
\text { Francinne de S.C. }\end{array}$ & $\begin{array}{l}\text { Enlace entre os estudos de usuários e os } \\
\text { paradigmas da ciência da informação: de } \\
\text { usuário a sujeitos pós-modernos }\end{array}$ & 2014 \\
\hline & $\begin{array}{c}\text { SANTOS, Raquel do } \\
\text { Rosário; DUARTE, } \\
\text { Emeide Nóbrega; LIMA, } \\
\text { Izabel França de } \\
\end{array}$ & $\begin{array}{c}\text { O papel do bibliotecário como mediador } \\
\text { da informação no processo de inclusão } \\
\text { social e digital }\end{array}$ & 2014 \\
\hline & $\begin{array}{l}\text { SANTA ANNA, Jorge; } \\
\text { PEREIRA, Gleice; } \\
\text { CAMPOS, Suelen de } \\
\text { Oliveira }\end{array}$ & $\begin{array}{c}\text { Sociedade da informação } \mathrm{x} \\
\text { biblioteconomia: em busca do moderno } \\
\text { profissional da informação (MIP) }\end{array}$ & 2014 \\
\hline
\end{tabular}




\begin{tabular}{|c|c|c|c|}
\hline \multirow{8}{*}{$\begin{array}{l}\text { Revista } \\
\text { Biblionline }\end{array}$} & $\begin{array}{l}\text { SANTANA, Vanessa } \\
\text { Alves; AQUINO, Mirian } \\
\text { de Albuquerque }\end{array}$ & $\begin{array}{l}\text { A responsabilidade social e ética e a } \\
\text { inclusão de afrodescendentes em } \\
\text { discursos de profissionais da informação } \\
\text { em universidade pública }\end{array}$ & 2009 \\
\hline & $\begin{array}{l}\text { ARAÚJO, Claudialyne da } \\
\text { Silva; SILVA, Edcleyton } \\
\text { Bruno Fernandes da; } \\
\text { SILVA, Alzira Karla } \\
\text { Araújo da }\end{array}$ & $\begin{array}{l}\text { Práticas de leitura e competências } \\
\text { profissionais do bibliotecário: um estudo } \\
\text { a partir dos trabalhos de conclusão do } \\
\text { curso de biblioteconomia / UFPB }\end{array}$ & 2010 \\
\hline & $\begin{array}{l}\text { SILVA, Marco Donizete } \\
\text { Paulino da et al. }\end{array}$ & $\begin{array}{c}\text { Estudo dos processos do setor de } \\
\text { reclamações da ideal transporte urbano } \\
\text { coletivo }\end{array}$ & 2010 \\
\hline & $\begin{array}{c}\text { ARAÚJO, Claudialyne da } \\
\text { Silva; GARCIA, Joana } \\
\text { Coeli Ribeiro }\end{array}$ & $\begin{array}{l}\text { A responsabilidade social no projeto } \\
\text { "estação do livro": leitura na praça }\end{array}$ & 2012 \\
\hline & $\begin{array}{l}\text { FREIRE, Isa Maria; } \\
\text { LIMA, Aline Poggi Lins } \\
\text { de; COSTA JUNIOR, } \\
\text { Maurício Pereira da }\end{array}$ & $\begin{array}{l}\text { Mídias sociais na web: de olho na CI para } \\
\text { capacitação acadêmica e profissional }\end{array}$ & 2012 \\
\hline & $\begin{array}{l}\text { CABRAL, Alice; LUCAS, } \\
\text { Elaine de Oliveira }\end{array}$ & $\begin{array}{l}\text { Serviço de referência no ambiente second } \\
\text { life (SL) }\end{array}$ & 2013 \\
\hline & $\begin{array}{l}\text { DANTAS, Esdras Renan } \\
\text { Farias; GARCIA, Joana } \\
\text { Coeli Ribeiro }\end{array}$ & $\begin{array}{c}\text { Do tradicional ao atual conceito de } \\
\text { responsabilidade social da ciência da } \\
\text { informação }\end{array}$ & 2013 \\
\hline & $\begin{array}{l}\text { CAVALCANTI, Ivanilda } \\
\text { Bezerra Cavalcanti; } \\
\text { ARAÚJO, Claudialyne } \\
\text { Silva; DUARTE, Emeide } \\
\text { Nóbrega }\end{array}$ & $\begin{array}{l}\text { O bibliotecário e as ações culturais: um } \\
\text { campo de atuação }\end{array}$ & 2015 \\
\hline
\end{tabular}

Fonte: o autor (2016).

Analisando cada um dos artigos, obedecendo-se a ordem a que se apresentam no quadro 2 , tem-se a pesquisa de Chagas (1996), cuja temática proposta pelo autor abordou as mudanças ocasionadas às práticas bibliotecárias, em virtude das transformações sociais vivenciadas nas últimas décadas do século XX.

$\mathrm{O}$ autor apresenta uma reflexão acerca do dinamismo que permeia o universo profissional para os profissionais da informação, principalmente para os bibliotecários. Considera, portanto, que os fazeres profissionais da atualidade, embora conservem muitas práticas tradicionais, ampliaram-se, de modo que a profissão vislumbra-se com um futuro promissor, havendo necessidades de conscientização entre profissionais, órgãos de classe e demais defensores da profissão.

Grande parte das mudanças ocasionadas às profissões deve-se, sobremaneira, ao avanço da tecnologia, nas últimas décadas. Essa discussão é apresentada na pesquisa de Ohira e Oliveira (1997), principalmente quando mencionam a realidade vivenciada por unidades de informação especializadas, sobretudo àquelas ligadas a uma intensa geração e fluxo de informação, como nos centros de informação jurídica.

Assim, é importante que os profissionais da informação da área jurídica dominem as técnicas e metodologias para gerenciar a informação que permeiam o contexto jurídico, sendo que esses profissionais tenham experiências na utilização das novas tecnologias de informação, e principalmente, preocupados em se capacitarem para enfrentar as exigências do mercado de trabalho, através dos cursos específicos, visando o atendimento aos usuários e as necessidades das instituições onde atuam (OHIRA; OLIVEIRA, 1997).

Uma das principais características que deve ter os profissionais que lidam com a 
informação nesses novos tempos diz respeito à capacidade de interatividade que devem ter, seja com demais profissionais, tecnologias, instituições e diferenciados usuários da informação (CHAGAS, 1997). Assim como refletiram Ohira e Oliveira (1997), Chagas (1997) também acredita que a tecnologia é a "mola propulsora" que viabiliza novas práticas profissionais, de modo a acarretar novas formas de comunicação no mundo moderno, por conseguinte, interferindo nas atitudes e comportamentos dos usuários. Sendo assim, a preocupação dos profissionais se amplia para além dos fazeres técnicos, condicionando novas reflexões acerca de fatores cognitivos e humanísticos.

Portanto, a tecnologia, ao mesmo tempo que substitui o fazer humano por processos mecanizados, desperta novas necessidades, principalmente no que se refere ao uso da informação. Assim, essas transformações constituem a delimitação de novos paradigmas, em que o rompimento "[...] de valores referente aos aspectos do ambiente organizacional, das pessoas, das atividades e do uso de novas tecnologias se interagem provocando um contínuo aprender do ser humano" (BLATTMANN; RADOS, 2000, p. 42).

Outra mudança provocada pelo avanço tecnológico e que afetou os fazeres dos profissionais da informação diz respeito à atuação integrada e holística que esses profissionais devem possuir. Ou seja, segundo a pesquisa de Caldin (2011), a tecnologia aproximou as pessoas e as práticas, por conseguinte, desperta o trabalho em equipe e a cultura da colaboração, o que exige capacidade reflexiva, pró-ativa e interventiva dos profissionais em suas práticas cotidianas.

Corrêa, Zamban e Oliveria (2013) acreditam no papel inovador do bibliotecário em face da incorporação das tecnologias aos fazeres profissionais. Citam, como exemplo, a gestão de blogs, um veículo de comunicação capaz de proporcionar uma imagem profissional muito mais positiva por meio de uma atuação presente e relevante na sociedade digital, quebrando estereótipos e construindo uma nova dimensão do que deve e pode ser o bibliotecário na atualidade.
Com efeito, as tecnologias proporcionam mudanças radicais. No entanto, esse fato deve ser considerado como uma oportunidade de crescimento no âmbito profissional, especialmente àquelas profissões que lidam com a informação, possibilitando 0 aparecimento de novas práticas diluídas em um mercado amplo, difuso e interdisciplinar. A ampliação dos fazeres bibliotecários para além das tradicionais bibliotecas, podendo o profissional atuar de forma autônoma, prestando serviços variados no mercado da informação, certamente, representa contribuições oriundas com essas mudanças (SANTA ANNA; PEREIRA, 2014).

De qualquer forma, o foco de atenção deve estar no usuário da informação, de modo que serviços e produtos oferecidos estejam em conformidade com as necessidades desse personagem. Desse modo, os profissionais da informação devem ser verdadeiros educadores quanto ao uso dos recursos informacionais oferecidos nas unidades de informação, principalmente àquelas em que há intenso fluxo informacional voltado para pesquisa, ensino e extensão, como nas bibliotecas universitárias (SCHWEITZER, 2007).

Ora, percebe-se a importância da educação voltada ao usuário e ao próprio profissional. Para Barros (2007), devem-se trabalhar estratégias pedagógicas, tendo em vista, um melhor acesso e uso da informação armazenada em diferentes suportes e acervos. $\mathrm{O}$ profissional da atualidade deve oferecer serviços de capacitação e aprimoramento a seus usuários, assim como também, deve capacitar-se a fim de ampliar suas competências para atender diferentes perfis, necessidades e variados desafios impostos pela sociedade.

Não resta dúvida de que, a sociedade globalizada está permeada por desafios a serem superados, o que consolida uma missão para os profissionais da informação, em virtude do dinamismo que a informação tomou nesse contexto inovador. A missão desse profissional deve ser a de facilitar os meios de acesso e uso da informação, considerando as mudanças e possibilidades ocasionadas pelas tecnologias digitais. Assim, confirma-se a preocupação humanística do profissional, a qual assume uma missão em 
benefício da coletividade, ou seja, oferece contribuições para o desenvolvimento humano e social (CARVALHO; REIS, 2007).

A partir do valor que a informação assume nesses novos tempos e a ampliação dos fazeres e práticas informacionais, evidenciase que os profissionais da informação, em destaque os bibliotecários, devem investir na formação continuada. Para Rocha e Araújo (2007), através de pesquisa realizada em instituições particulares de João Pessoa, os bibliotecários redesenvolvem ações de educação continuada (cursos de mestrado, especialização, participação em eventos etc.). Além disso, importante discorrer que essas ações têm se concentrado no manuseio de tecnologias de informação e postura gerencial.

Além das questões humanas, sociais, gerenciais e tecnológicas apontadas até aqui, deve-se considerar, também, novas estratégias a serem utilizadas pelos profissionais que atuam no âmago do tratamento técnico da informação. $\mathrm{Na}$ atualidade, esses fazeres não devem se preocupar, tão somente, com o armazenamento documental, mas deve-se, outrossim, centrarem-se na recuperação da informação. Desse modo, para que os sistemas de recuperação da informação auxiliados pelas novas tecnologias tenham eficiência, deve-se utilizar instrumento de controle do vocabulário de forma adequado, de modo que se possam registrar a linguagem especializada e as possíveis variações terminológicas (VAN DER LAAN; ALVORCEM, 2007).

Os métodos e técnicas de recuperação da informação devem favorecer a autonomia do usuário, permitindo-lhe ampla possibilidade de busca e acesso às coleções armazenadas nos acervos, sejam eles físicos quanto digitais. No que se refere à busca e recuperação de informação nos ambientes digitais, o trabalho profissional na elaboração de interfaces amigáveis permite uma maior aproximação dos usuários, rompendo-se limitações temporais e espaciais (MOREIRA; CARVALHO, 2008).

Nesse sentido, observa-se uma missão desencadeada pela Ciência da Informação, qual seja, permitir maior aproximação da informação aos seus usuários. Portanto, segundo o estudo realizado por Becker e Grosch (2008), o profissional atual deve atuar na formação de usuários autodidatas, que sejam capazes de entender as ferramentas disponíveis e utilizá-las em favor da localização e melhor aproveitamento informacional.

Novamente, detecta-se a visão e preocupação cognitiva da Ciência da Informação, a qual se sustenta em um modelo paradigmático, cujo foco é o uso da informação e o comportamento do usuário nesse contexto. Segundo Fernandes (2011), a grande contribuição da Ciência da Informação está no fato de viabilizar a passagem do modelo matemático ao ponto de vista cognitivo, tendo como objetivo central, a partir dessa transformação, gerar mudança de uma abordagem de acesso à informação centrado na informação para a de acesso à informação centrado no usuário.

A importância em viabilizar o acesso e uso da informação, de modo a agregar valor para o sujeito, desencadeando um contexto de competitividade e busca constante ao conhecimento, é conseqüência das transformações provocadas com o fim da Segunda Guerra Mundial e a partir das tendências competitivas oriundas da Guerra Fria. A Ciência da Informação nasce a partir dessa preocupação em tornar a informação cada vez mais fácil de ser armazenada, acessada e utilizada, haja vista provocar mudanças no contexto humano e social de quem a utiliza (SANTOS JUNIOR, 2012).

Nesse sentido, os paradigmas inerentes a esse campo do conhecimento são amplos, de modo a contribuir com o surgimento de novas práticas profissionais, sobretudo no âmago das novas tecnologias. De acordo com a tese de Medeiros (2012, p. 113), pode-se entender que tal área "[...] evoluiu de forma a tratar a informação primeiramente de forma quantitativa, posteriormente de forma a avaliar os processos cognitivos individualizados dos usuários e, por fim, buscando agregar contexto social aos sistemas de recuperação da informação".

A Ciência da Informação é, pois, uma ciência da contemporaneidade, ou seja, uma área em expansão, a qual constitui um importante personagem para a evolução e 
permanência de inúmeras profissões na sociedade atual. Sua contribuição está no fato de proporcionar teorias e fundamentações suficientes para provocar descobertas a inúmeros problemas enfrentados pelo mercado da informação (SIQUEIRA, 2012).

Em virtude da importância que a informação possui no desenvolvimento humano e social, afere-se que a Ciência da Informação, diante de uma sociedade em que predominam ideias liberais e democráticas, coloca-se a serviço da consolidação da cidadania, o que garante o aspecto social presente nos paradigmas e fundamentos dessa ciência. Assim, desperta-se a viabilidade de práticas profissionais que condicionem uma sociedade mais inclusiva para todos (ISHIKAWA; BELLUZZO, 2013).

Além das questões inclusivas, discute-se o papel da informação quanto à sobrevivência das organizações em um contexto competitivo e mutante. De acordo com os estudos de Alves e Duarte (2014), as organizações devem considerar a informação, assim como as forças que sustentam o seu fluxo, como a principal preocupação, o que requer novos métodos de trabalho e novos modelos de gerenciamento.

Semelhante ao trabalho de Ishikawa e Belluzzo (2013), Tanus (2014) considera que a Ciência da informação está embasada em um paradigma sociocultural. Para essa autora, o objeto de estudo da área está nas pessoas, ou seja, nos sujeitos pós-modernos, o que requer a atuação profissional voltada para questões cognitivas e comportamentais.

No entendimento de Santos, Duarte e Lima (2014), as profissões da informação devem, a princípio, preocuparem-se com o acesso à informação, por conseguinte, viabilizar a inclusão social dos sujeitos, favorecendo o acesso às tecnologias, como também ao desenvolvimento de habilidades e competências associadas ao uso desses recursos. Nesse enfoque, não resta dúvida de que, o sujeito informado torna-se atuante na busca e exigência de seus direitos, dessa maneira, é responsabilidade social dos profissionais da informação atuar no processo de inclusão desses sujeitos para gerar conhecimento.
A atuação interdisciplinar em prol de uma prática profissional mais humanizada, social e cultural não deve ser a única abordagem das ciências que lidam com a informação. Essas constituem uma das competências dos profissionais da informação que, para serem inovadores, deverão adotar outras competências, comungando uma mistura de habilidades, de forma a desencadear uma atuação híbrida, em diferentes contextos (SANTA ANNA; PEREIRA; CAMPOS, 2014).

Um exemplo de prática social, cultural e humanizada é apresentada na pesquisa de Santana e Aquino (2009), para quem, os profissionais modernos devem orientar-se por meio de uma responsabilidade social e ética, cujo objetivo seja consolidar uma sociedade mais igualitária, sem preconceitos ou quaisquer tipos de discriminação, sobretudo com indivíduos afrodescendentes. Os autores acreditam que os profissionais devem buscar conhecimentos interdisciplinares, promovendo a disseminação da informação, atividade que norteia as ações dos profissionais da informação.

A construção de uma sociedade democrática, cidadã e igualitária é também discorrida no estudo de Araújo, Silva e Silva (2010). Consideram que a leitura, especialmente, na sociedade da informação, representa uma prática informacional que possibilita a construção do conhecimento sustentado pela aprendizagem, auxiliando a formação cidadã.

A construção cidadã, em grande parte, é sustentada pelo acesso à informação e conhecimento. No estudo de Silva e outros (2010), apresenta-se a importância de se estabelecer modelos de gestão e práticas profissionais de tratamento informacional de modo a melhorar o fluxo informacional de uma organização de transporte coletivo. Se todas as fases do ciclo documentário forem devidamente gerenciadas, certamente o fluxo da informação proporcionará melhoria na tomada de decisões, bem como tende a garantir melhor qualidade nas informações fornecidas a colaboradores e clientes no ambiente organizacional.

A atuação do profissional no sentido de promover ações das mais variadas, a partir de 
planejamento e projetos que despertem o incentivo à leitura e o gosto pela cultura e pelo conhecimento é de viável importância. Portanto, cabe ao profissional da informação desenvolver ações planejadas de práticas de leitura e de responsabilidade social culminando em um processo contínuo de inclusão e cidadania (ARAÚJO; GARCIA, 2012).

Não resta dúvida de que os novos recursos oriundos com o avanço tecnológico contribuem para que novas ações sejam realizadas, e se manifesta uma maior aproximação entre a informação e o usuário. Assim, segundo relatam Freire, Lima e Costa Júnior (2012), o uso das tecnologias, através da criação e disponibilização de produtos e serviços no ambiente digital, contribui na satisfação do usuário quanto na divulgação dos produtos e serviços mantidos pelos profissionais.

Com o uso dos recursos disponibilizados no ambiente digital, as práticas profissionais ampliam-se para o ambiente web, sustentando a formação das bibliotecas digitais, as quais garantem inúmeros benefícios aos usuários. Dentre esses benefícios, o serviço de referência virtual, por exemplo, constitui uma estratégia viável, tendo em vista garantir maior aproximação do usuário com as práticas informacionais, assim como visa a garantir maior satisfação e qualidade ao que é ofertado (CABRAL; LUCAS, 2013).

Com efeito, percebe-se a interdisciplinaridade e amplitude inerente à Ciência da Informação, a qual viabiliza inúmeras práticas profissionais que contribuirão para uma efetiva gestão da informação em diferentes contextos. De acordo com Dantas e Garcia (2013, p. 4, grifo nosso), essa área manifesta-se como ciência social, tendo a missão de identificar, por meio de pesquisas, "[...] a viabilização de recursos informacionais, tecnológicos ou não, que almejem atender as necessidades dos sujeitos, seja pelo tratamento, disponibilização, acesso e uso da informaçãa".

Entende-se que essas práticas ao viabilizarem a informação com qualidade, objetivam, a posteriori, promover aprendizado e transformação pessoal e social, logo, estão ligadas à cidadania e à cultura de uma dada coletividade. Portanto, percebe-se a importância que as áreas da informação possuem para com o progresso das nações, assim como defende Cavalcanti, Araújo e Duarte (2015), ao mencionarem o importante papel das ações sociais e culturais que podem ser desenvolvidas em diferentes unidades de informação e centros de cultura. Consideram as autoras que as ações culturais são produtos da própria sociedade, por isso, representam uma oportunidade do profissional engajar-se com as causas sociais, aumentando sua valorização e reconhecimento em prol de uma sociedade democrática, igualitária e cidadã.

\subsection{ANÁLISE E DISCUSSÃO}

Os 31 artigos analisados abordam reflexões semelhantes acerca do papel que a Ciência da Informação desempenha no cenário contemporâneo, principalmente com o desenvolvimento tecnológico, o qual promoveu a expansão da produção informacional, assim como sua valorização na sociedade. Em linhas gerais, analisando as contribuições que essa ciência viabiliza aos fazeres profissionais no âmbito da indústria da informação, afere-se algumas práticas discorridas nos parágrafos seguintes.

Primeiramente, é preciso considerar uma maior aproximação dessas práticas no bojo da Biblioteconomia, conforme relatado por Souza (1996), o qual destaca uma prática híbrida direcionada à atuação do bibliotecário, que se sustenta por meio de uma prática profissional humanista e outra prática bibliotecária racionalizadora.

A questão dos fazeres técnicos, voltados à produção, tratamento $\mathrm{e}$ armazenamento (ciclo informacional) é relatada em quase todos os estudos (OHIRA; OLIVEURA, 1997; VAN DER LAAN; ALVORCEM, 2007; SANTA ANNA; PEREIRA, 2014, dentre outros), sendo que essa preocupação não constitui uma novidade, uma vez que já permeiam as práticas tradicionais das profissões que lidam com a informação.

A ampliação do ciclo informacional, a qual se estende à questão da disseminação, do acesso e do uso da informação é apresentada em alguns estudos (BLATTMANN; RADOS, 2000; 
SCHWEITZER, 2007; CALDIN, 2011). Assim, a Ciência da Informação fomenta uma atuação que extravasa, tão somente, o acesso, mais viabiliza a apropriação e geração de conhecimento pelo usuário.

Com efeito, pensar nas possibilidades de disponibilização da informação no ambiente eletrônico, em virtude dos novos recursos oferecidos nesse espaço cria preocupações mais abrangentes, como a questão da comunicabilidade e interatividade, como também, viabiliza novos métodos para recuperação da informação, sobretudo com o desenvolvimento de sistemas de recuperação integrados e disponibilizados no ambiente web (SOUZA, 2007; MOREIRA; CARVALHO, 2008; SIQUEIRA, 2012; SANTA ANNA; PEREIRA, CAMPOS, 2014).

Não resta dúvida de que, a tecnologia proporciona novas formas de atuação profissional. Com isso, ampliam-se as práticas, os métodos, as técnicas, sendo necessário estabelecer modelos de gestão para que a informação se propague em meio a fluxos bem delimitados e monitorados. Essas práticas consolidam a participação dos profissionais da informação no contexto empresarial e em outros ambientes que demandem gestão da informação, sendo necessária a constante capacitação profissional (BARROS, 2007; CARVALHO; REIS, 2007; ROCHA; ARAÚJO, 2007; SILVA, 2010; SANTOS; JUNIOR, 2012).

Observa-se com essa expansão, uma prática profissional desinstitucionalizante, ou seja, realizada além dos ambientes tradicionais como nas unidades de informação, assim como defendeu Lancaster (1983). Assim, a Ciência da Informação viabiliza práticas profissionais em que demandem trabalho interdisciplinar com o auxílio das novas tecnologias na resolução de diferenciados problemas, o que consolida uma atuação autônoma, inovadora e audaciosa por parte do profissional, atuando em diferentes ambientes, instâncias e contextos (CORRÊA; ZAMBAN; OLIVEIRA, 2013; FREIRE; LIMA; COSTA JUNIOR, 2012; SANTA ANNA; PEREIRA, 2014).

Portanto, observa-se a ampliação de práticas profissionais direcionadas às profissões que lidam com a informação. Essa expansão além do tratamento técnico viabiliza um novo paradigma a ser considerado pelas profissões da informação, ou seja, deixa-se de centrar apenas no documento/informação para adentrar-se ao usuário, fato esse que envolve questões cognitivas e comportamentais (CARVALHO; REIS, 2007; FERNANDES, 2011; TANUS, 2014).

A preocupação com o acesso e uso da informação, logo, o foco das atenções direcionado ao usuário constitui, outrossim, uma das preocupações dos estudos desenvolvidos pela Ciência da Informação. Entender o comportamento desse personagem e compreender suas necessidades são estratégias que promovem a qualificação dos produtos e serviços oferecidos, tendo em vista a melhoria contínua das práticas realizadas (BECKER; GROSCH, 2008; ARAÚJO, SILVA.; SILVA, 2010; ARAÚJO; GARCIA, 2012).

Nesse contexto, os serviços oferecidos de modo a compreender a realidade do usuário, bem como a prestação de atendimento personalizado e qualificado constituem ações que demonstram o papel social da Ciência da Informação. Portanto, não resta dúvida do valor que as unidades de informação adquirem ao oferecer condições para conhecer o usuário e propor melhorias que gerem satisfação (ARAÚJO; SILVA; SILVA, 2010; CABRAL; LUCAS, 2013; DANTAS; GARCIA, 2013).

Por fim, ao considerar a realidade e necessidades dos usuários, práticas devem ser fomentadas no sentido de identificar as dificuldades e limitações que problematizam, de alguma forma, o acesso à informação, como relatado nos estudos sobre a questão da inclusão social (SANTANA; AQUINO, 2009; MEDEIROS, 2012; ISHIKAWA; BELLUZZO, 2013). Sendo assim, através dessa nova concepção social, as profissões, seus profissionais e a Ciência da Informação tomam como base em suas práticas interventivas, propor soluções para inúmeros problemas, de modo a tornar a sociedade cada dia mais inclusiva, democrática, igualitária e, principalmente, que fomente a cidadania no contexto social (ALVES; DUARTE, 2014; SANTOS; DUARTE; LIMA, 2014; 
CALVALCANTI; ARAÚJO, DUARTE, 2015).

\section{CONSIDERAÇÕES FINAIS}

Por meio da revisão de literatura foi possível caracterizar e conceituar a Ciência da Informação, considerada como área do conhecimento que gerencia a informação através de diferentes tecnologias e em todas as instâncias e contextos informacionais. Constatou-se que essa ciência ainda carece de uma identidade própria, assim como inexiste um sistema de jurisdição a seu favor. Desse modo, os estudos científicos dessa área viabilizam inúmeras práticas profissionais, contribuindo para o desenvolvimento das profissões que lidam com a informação, tendo maior aproximação com a Biblioteconomia, mas também contribuindo com $\mathrm{O}$ desenvolvimento da Arquivologia e Museologia.

Em linhas gerais, os artigos analisados nesta revisão apresentaram como principais práticas profissionais viabilizadas pela Ciência da Informação: fazeres técnicos, voltados à produção, tratamento $\mathrm{e}$ armazenamento; ampliação do ciclo informacional, a qual se estende à questão da disseminação, do acesso e do uso da informação; práticas de comunicabilidade, interatividade e recuperação da informação; práticas de gestão da informação e seus fluxos; trabalho interdisciplinar em meio à atuação autônoma, inovadora e audaciosa; ações a favor do usuário, conhecendo seu perfil, necessidades, limitações e seu comportamento; prestação de atendimento personalizado e qualificado; e, por fim, ações de inclusão social, por meio de práticas interventivas, as quais viabilizem a construção da cidadania, desencadeando uma sociedade mais inclusiva, democrática e igualitária.

Percebe-se, com base nas práticas citadas, que a Ciência da Informação coloca-se a serviço das profissões da informação, realizando estudos acerca dos problemas abrangentes que permeiam a sociedade, e que, tradicionalmente, não eram preocupações primordiais dessas profissões. Portanto, a Ciência da Informação configura-se como uma ciência auxiliar, contribuindo para a evolução, inovação, aperfeiçoamento e permanência de muitas profissões no mercado competitivo da atualidade.

Constata-se, também, o aspecto multifacetado dessa ciência ao propor diferentes concepções para as profissões na sociedade: uma concepção tecnicista, em que pese os fazeres técnicos, mecânicos, regidos por regras, tecnologias e procedimentos, e uma concepção humanista, direcionada ao ser humano e suas limitações como elemento natural e social, adentrando-se a aspectos cognitivos e comportamentais. Nessas duas vertentes, confirma-se que a Ciência da Informação manifesta-se como ciência social, a qual converge para o desenvolvimento da sociedade e adequação do fator humano enquanto elemento principal desse contexto.

Recebido em: 20/01/2017

Aceito em definitive em: 17/04/2017

\section{PROFESSIONAL PRACTICES IN INFORMATION SCIENCE: A REVIEW IN BRAZILIAN LITERATURE}

\section{Abstract}

Thematizes the Information Science and its relations with the professionalism. It aims to present professional practices coming from Information Science and its contribution to the information professions. In addition, the research explores concepts and main characteristics inherent in the area of Information Science. The methodological procedures 
were based on literature review in articles published in professional journals. After analysis and discussion, with 31 articles selected for review, it was verified that the Information Science fosters numerous professional practices, such as: technical tasks, focused on production, treatment and storage; Expansion of the information cycle, which extends to the issue of dissemination, access and use of information; Practices of communicability, interactivity and information retrieval; Information management practices and their flows; Interdisciplinary work in the midst of autonomous, innovative and audacious work; Actions in favor of the user, knowing their profile, needs, limitations and their behavior; Providing personalized and qualified service; And, finally, actions of social inclusion, through interventional practices, which enable the construction of citizenship, triggering a more inclusive, democratic and egalitarian society. These practices demonstrate the technical and humanistic conception inherent in Information Science, therefore, characterizes this field of knowledge as a social area for the adequacy of the human factor, as the main element of the social context.

Keywords: Information and Communication Technologies. Access and use of information. Information Science. Professional practices in Information Science.

\section{REFERÊNCIAS}

ABBOTT. The system of professions: na essay on the division of expert labour. Chigago: The University of Chicago Press, 1988.

ALVES, Rachel Cristina Vesu. Ciência da Informação, Ciência da Computação e Recuperação da Informação: algumas considerações sobre os métodos e tecnologias da informação utilizados ao longo dos tempos. Informação e Cognição, v. 6, n. 1, p. 28-40, 2007. Disponível em:

<www.brapci.ufpr.br/download.php?dd0=841 0>. Acesso em: 15 mar. 2016.

ALVES, Claudio Augusto; DUARTE, Emeide Nobrega Duarte. Revista Brasileira de Biblioteconomia e Documentação. São

Paulo, v. 10, n. 1, p. 2-20, jan./jun. 2014. Disponível em:

<http://rbbd.febab.org.br/rbbd/article/view/27 5/285>. Acesso em: 28 mar. 2016.

ARAÚJO, Carlos Alberto Ávila. Ciência da Informação como campo integrador para as áreas de Biblioteconomia, Arquivologia e Museologia. Informação e Informação, Londrina, v. 15, n. 1, p. 173 - 189, jul./jun. 2010. Disponível em:
<file:///C:/Users/Guest/Downloads/4744-

23580-4-PB.pdf>. Acesso em: 23 mar. 2016.

. Arquivologia, Biblioteconomia, Museologia e Ciência da Informação: o diálogo possível. Brasília: Briquet de Lemos, 2014.

ARAÚJO, Claudialyne da Silva; SILVA, Edcleyton Bruno Fernandes da; SILVA, Alzira Karla Araújo da. Práticas de leitura e competências profissionais do bibliotecário: um estudo a partir dos trabalhos de conclusão do curso de biblioteconomia / UFPB.

Biblionline, João Pessoa, n. esp., p. 117-125, 2010. Disponível em:

<http://periodicos.ufpb.br/ojs2/index.php/bibl io/article/view/9630/5243>. Acesso em: 23 mar. 2016.

ARAÚJO, Claudialyne da Silva; GARCIA, Joana Coeli Ribeiro. A responsabilidade social no projeto "estação do livro": leitura na praça. Biblionline, João Pessoa, v. 8, n. 2, p. 110, 2012. Disponível em: < http://periodicos.ufpb.br/ojs2/index.php/biblio /article/view/12478/8642>. Acesso em: 26 mar. 2016.

BARBOSA, Ricardo Rodrigues. Perspectivas profissionais e educacionais em biblioteconomia e ciência da informação. 
Ciência da Informação, Brasília, v. 27, n. 1, p. 53-60, jan./abr. 1998. Disponível em: <http://www.scielo.br/pdf/ci/v27n1/07.pdf>. Acesso em: 22 mar. 2016.

BARROS, Daniela Melaré Vieira. Ambientes mediatizados para a formação continuada dos profissionais da informação. Revista

Brasileira de Biblioteconomia e Documentação, Nova Série, São Paulo, v.3, n.2, p.56-66, jul-dez. 2007. Disponível em: < http://rbbd.febab.org.br/rbbd/article/view/70/5 9>. Acesso em: 28 mar. 2016.

BECKER, Caroline da Rosa Ferreira; GROSCH, Maria Selma. A formação do leitor através das bibliotecas: o letramento e a ciência da informação como pressupostos.

Revista Brasileira de Biblioteconomia e Documentação, Nova Série, São Paulo, v.4, n.1, p. 35-45, jan./jun. 2008. Disponível em: <http://rbbd.febab.org.br/rbbd/article/view/59 179>. Acesso em: 30 mar. 2016.

BLATTMANN, Úrsula; RADOS, Gregório J. Varvakis. Bibliotecários na sociedade da informação: mudança de rótulos, funções ou habilidades? Revista ACB: Biblioteconomia em Santa Catarina, v.5, n.5, 2000.

Disponível em:

<file:///C:/Users/Guest/Desktop/344-1460-1PB.pdf>. Acesso em: 28 mar. 2016.

BORKO, Harold. Information science: what is it? American Documentation, v.19, n.1, p. 3-5, 1968.

BRASIL. Ministério do Trabalho e Emprego. Classificação brasileira de ocupações. 2002. Disponível em:

<http://www.mtecbo.gov.br/busca/descricao.a sp?codigo $=2612-05>$. Acesso em: 15 mar. 2016.

CABRAL, Alice; LUCAS, Elaine de Oliveira. Serviço de referência no ambiente second life (SL). Biblionline, João Pessoa, v. 9, n. 1, p. 61-73, 2013. Disponível em: < http://periodicos.ufpb.br/ojs2/index.php/biblio /article/view/13569/9594>. Acesso em: 28 mar. 2016.
CALDIN, Clarice Fortkamp. Atuação do bibliotecário diante da globalização da informação. Revista ACB: Biblioteconomia em Santa Catarina, Florianópolis, v.16, n.1, p. 381-390, jan./jun., 2011. Disponível em: <http://revista.acbsc.org.br/racb/article/view/7 85/pdf_56>. Acesso em: 28 mar. 2016.

CARVALHO, Kátia de; REIS, Marivaldina Bulcão. Missão do bibliotecário: a visão de José Ortega y Gasset. Revista Brasileira de Biblioteconomia e Documentação, Nova Série, São Paulo, v.3, n.2, p.34-42, jul./dez. 2007. Disponível em:

<http://rbbd.febab.org.br/rbbd/article/view/63 /58>. Acesso em: 30 mar. 2016.

CAVALCANTI, Ivanilda Bezerra Cavalcanti; ARAÚJO, Claudialyne Silva; DUARTE, Emeide Nóbrega. O bibliotecário e as ações culturais: um campo de atuação. Biblionline, João Pessoa, v. 11, n. 1, p. 21-34, 2015.

Disponível em: <

http://periodicos.ufpb.br/ojs2/index.php/biblio /article/view/16626/14651>. Acesso em: 28 mar. 2016.

CUNHA, Mirian Vieira da. As profissões e as suas transformações na sociedade. In: ; SOUZA; Francisco das Chagas de (Org.). Comunicação, gestão e profissão: abordagens para o estudo da Ciência da Informação. Belo Horizonte: Autêntica, 2006, p. $141-150$.

DANTAS, Esdras Renan Farias; GARCIA, Joana Coeli Ribeiro. Do tradicional ao atual conceito de responsabilidade social da ciência da informação. Biblionline, João Pessoa, v. 9, n. 2, p. 3-18, 2013. Disponível em:

<http://periodicos.ufpb.br/ojs2/index.php/bibl io/article/view/15281/10157>. Acesso em: 29 mar. 2016.

ECHER, Isabel Cristina. A revisão de literatura na construção do trabalho científico. Revista Gaúcha de Enfermagem, Porto Alegre, v. 22, n. 2, jul. 2001.

FARIAS, Gabriela Belmont de; VITAL, Luciane Paula. Informação para negócios e políticas de informação. Revista ACB: 
Biblioteconomia em Santa Catarina, Florianópolis, v.12, n.1, p. 87-98, jan./jun., 2007. Disponível em:

$<$ http://revista.acbsc.org.br/racb/article/view/4 97/642>. Acesso em: 28 mar. 2016.

FERNANDES, Marcia Leite. O cognitivismo na CI: a leitura de Ingwersen e a passagem do modelo matemático ao cognitivo. Revista

Brasileira de Biblioteconomia e

Documentação. São Paulo, v.7, n.2, p. 140-

155, jul./dez. 2011. Disponível em:

<http://rbbd.febab.org.br/rbbd/article/view/15

7/204>. Acesso em: 28 mar. 2016.

FREIRE, Isa Maria; LIMA, Aline Poggi Lins de; COSTA JUNIOR, Maurício Pereira da. Mídias sociais na web: de olho na CI para capacitação acadêmica e profissional.

Biblionline, João Pessoa, v. 8, n. esp., p. 175184, 2012. Disponível em: <

http://periodicos.ufpb.br/ojs2/index.php/biblio /article/view/14202/8108>. Acesso em: 23 mar. 2016.

FROEHLICH, Thomas. Velhos princípios, novas aplicações: a evolução das profissões da informação. In: SILVA, Helen de Castro; BARROS, Maria Helena. Ciência da Informação: múltiplos diálogos. Marília: Oficina Universitária Unesp, 2009, p. 89-109.

ISHIKAWA, Maria Inês Garcia; BELLUZZO, Regina Célia Baptista. Práticas inclusivas para deficientes visuais, baseadas na informação e conhecimento: reflexões e ações. Revista Brasileira de Biblioteconomia e Documentação. São Paulo, v.9, n.2, p. 147-164, jul./dez. 2013. Disponível em: <

http://rbbd.febab.org.br/rbbd/article/view/255/ 266 >. Acesso em: 28 mar. 2016.

LANCASTER, Frederick Wilfrid. Future librarianship: preparing for an unconventional career. Wilson Library Bulletin, v. 57, p. 747-53, May 1983.

LE COADIC, Yves-François. A ciência da informação. 2. ed. Brasília: Briquet de Lemos, 2004.
MCGARRY, Kevin. O Contexto dinâmico

da informação: uma análise introdutória. Brasília: Briquet de Lemos, 1999.

MEDEIROS, Jackson da Silva. Considerações sobre a informação na terceira ordem da ordem: um olhar a partir dos paradigmas da Ciência da Informação.

Revista Brasileira de Biblioteconomia e Documentação. São Paulo, v.8, n.2, p. 102115, jul./dez. 2012. Disponível em: $<$ http://rbbd.febab.org.br/rbbd/article/view/18 9/232>. Acesso em: 28 mar. 2016.

MOREIRA, Jonatan; CARVALHO, José Oscar Fontanini de. Estudo de métodos e técnicas da ciência da informação aplicáveis à educação a distância. Revista Brasileira de Biblioteconomia e Documentação, nova Série, São Paulo, v.4, n.2, p. 15-32, jul./dez. 2008. Disponível em:

<http://rbbd.febab.org.br/rbbd/article/view/10 3/121>. Acesso em: 28 mar. 2016.

MUELLER, Suzana Pinheiro Machado. Profissional da Informação na ótica de Abbott. In: BAPTISTA, Sofia Galvão; MUELLER, Suzana Pinheiro Machado (Org). Profissional da informação: o espaço de trabalho. Brasília: Thesaurus, 2004. . A ciência, o sistema de comunicação científica e a literatura científica. In: CAMPELO, Bernadete dos Santos; CENDÓN, Beatriz Valadares; KREMER, Jeannette Marguerite (org). Fontes de informação para pesquisadores e profissionais. Belo Horizonte: Ed. UFMG, 2003, p. 21-35.

RIBAS, Cláudia S. da Cunha; ZIVIANI, Paula. O profissional da informação: rumos e desafios para uma sociedade inclusive.

Informação e Sociedade: estudos, João Pessoa, v. 17, n. 3, p. 47-57, set./dez. 2007. Disponível em:

<http://www.ies.ufpb.br/ojs/index.php/ies/arti cle/viewFile/638/1614>. Acesso em: 24 mar. 2016.

ROCHA, Maria Meriane Vieira; ARAÚJO, Eliany Alvarenga de. Educação continuada de 
profissionais da informação: perfil da ação de bibliotecários de instituições de ensino superior privado no município de João Pessoa - PB. Revista Brasileira de Biblioteconomia e Documentação, Nova Série, São Paulo, v.3, n.2, p.89-99, jul./dez. 2007. Disponível em:

<http://rbbd.febab.org.br/rbbd/article/view/62 |55>. Acesso em: 29 mar. 2016.

RUSSO, M. Fundamentos de Biblioteconomia e Ciência da Informação. Rio de Janeiro: E-papers, 2010.

SANTANA, Vanessa Alves; AQUINO, Mirian de Albuquerque. A responsabilidade social e ética e a inclusão de afrodescendentes em discursos de profissionais da informação em universidade pública. Biblionline, João Pessoa, v. 5, n. 1/2, 2009. Disponível em: < http://periodicos.ufpb.br/ojs2/index.php/biblio /article/view/3945/3110>. Acesso em: 29 mar. 2016.

SANTA ANNA, Jorge; PEREIRA, Gleice. Ampliando o campo de atuação bibliotecária: o bibliotecário como consultor informacional. Revista ACB: Biblioteconomia em Santa Catarina, Florianópolis, v. 19, n. 2, p. 163173, jul./dez., 2014. Disponível em: < http://revista.acbsc.org.br/racb/article/view/95 6/pdf_96>. Acesso em: 28 mar. 2016.

SANTA ANNA, Jorge; PEREIRA, Gleice; CAMPOS, Suelen de Oliveira. Sociedade da informação x biblioteconomia: em busca do moderno profissional da informação (MIP).

Revista Brasileira de Biblioteconomia e Documentação. São Paulo, v. 10, n. 1, p. 6885, jan./jun. 2014. Disponível em: < http://rbbd.febab.org.br/rbbd/article/view/293/ 293>. Acesso em: 28 mar. 2016.

SANTOS, Raquel do Rosário; DUARTE, Emeide Nóbrega; LIMA, Izabel França de. O papel do bibliotecário como mediador da informação no processo de inclusão social e digital. Revista Brasileira de

Biblioteconomia e Documentação. São Paulo, v. 10, n. 1, p. 36-53, jan./jun. 2014. Disponível em: <http://rbbd.febab.org.br/rbbd/article/view/27 9/289>. Acesso em: 28 mar. 2016.

SANTOS JUNIOR, Roberto Lopes. Análise sobre o desenvolvimento do campo de estudo em informação científica e técnica nos Estados Unidos e na antiga União Soviética durante a guerra fria (1945-1991). Revista

Brasileira de Biblioteconomia e

Documentação. São Paulo, v.8, n.2, p. 130157, jul./dez. 2012. Disponível em: <http://rbbd.febab.org.br/rbbd/article/view/21 7/233>. Acesso em: 28 mar. 2016.

SARACEVIC, Tefko. Ciência da informação: origem, evolução e relações. Perspectiva em Ciência da Informação, Belo Horizonte, v. 1, n. 1, p. 41-62, jan./jun. 1996. Disponível em: < file:///C:/Users/Guest/Desktop/235630-1-PB.pdf $>$. Acesso em: 17 mar. 2016.

SCHWEITZER, Fernanda. Os novos perfis dos profissionais da informação nas bibliotecas universitárias. Revista Brasileira de Biblioteconomia e Documentação, Nova Série, São Paulo, v. 3, n. 2, p. 80-88, jul./dez. 2007. Disponível em: < http://rbbd.febab.org.br/rbbd/article/view/45/5 0>. Acesso em: 28 mar. 2016.

SILVA, Marco Donizete Paulino da et AL. Estudo dos processos do setor de reclamações da ideal transporte urbano coletivo.

Biblionline, João Pessoa, v. 6, n. 2, p. 56-74, 2010. Disponível em: <http://periodicos.ufpb.br/ojs2/index.php/bibl io/article/view/7525/5522>. Acesso em: 29 mar. 2016.

SIQUEIRA, Jessica Câmara. Ciência da Informação: personagem da pósmodernidade. Revista Brasileira de Biblioteconomia e Documentação. São Paulo, v.8, n.1, p. 14-33, jan./jul. 2012. Disponível em:

<http://rbbd.febab.org.br/rbbd/article/view/18 6/217>. Acesso em: 28 mar. 2016.

SMIT, Johanna. O profissional da informação e sua relação com as áreas de

Biblioteconomia/Documentação, Arquivologia e Museologia. In: VALENTIM, 
Marta Lígia (Org.). Profissionais da informação: formação, perfil e atuação profissional. São Paulo: Polis, 2000. p. 119134.

SOUZA, Francisco das Chagas de. As diferentes praticas bibliotecárias brasileiras e sua relação com o futuro da educação profissional. Revista ACB: Biblioteconomia em Santa Catarina, Florianópolis, v. 1, n. 1, 1996. Disponível em:

<file:///C:/Users/Guest/Desktop/307-1272-1PB.pdf >. Acesso em: 28 mar. 2016. . Interatividade comunicacional no terceiro milênio. Revista ACB:

\section{Biblioteconomia em Santa Catarina,}

Florianópolis, v. 2, n. 2, 1997. Disponível em: $<$

http://revista.acbsc.org.br/racb/article/view/31 7/364>. Acesso em: 28 mar. 2016.

O discurso sobre a educação em

Biblioteconomia e Ciência da Informação no Brasil: caminhos teóricos-metodológicos para a compreensão. In: CUNHA, Mirian Vieira da; SOUZA; Francisco das Chagas de (Org.). Comunicação, gestão e profissão: abordagens para o estudo da Ciência da Informação. Belo Horizonte: Autêntica, 2006, p. 151-172.
TANUS, Gabrielle Francinne de S.C. Enlace entre os estudos de usuários e os paradigmas da ciência da informação: de usuário a sujeitos pós-modernos. Revista Brasileira de Biblioteconomia e Documentação. São Paulo, v. 10, n. 2, p. 144-173, jul./dez. 2014. Disponível em: < http://rbbd.febab.org.br/rbbd/article/view/290/ 384>. Acesso em: 28 mar. 2016.

VALENTIM, Marta Lígia Pomim. Inteligência competitiva em organizações: dado, informação e conhecimento.

DataGramaZero, Rio de Janeiro, v. 3, n. 4, p. 1-13, ago. 2002. Disponível em: <http://www.dgz.org.br/ago02/Art_02.htm>. Acesso em: 16 mar. 2016.

VAN DER LAAN, Regina Helena; ALVORCEM, Rochelle Martins. A terminologia expressa no discurso dos especialistas da área da ciência da informação: um estudo de caso. Revista

Brasileira de Biblioteconomia e Documentação, Nova Série, São Paulo, v.3, n.2, p.107-115, jul./dez. 2007. Disponível em: <http://rbbd.febab.org.br/rbbd/article/view/53 /54>. Acesso em: 29 mar. 2016.

\footnotetext{
${ }^{1}$ Os resultados parciais deste estudo foram apresentados no X Encontro da Associação de Educação e Pesquisa em Ciência da Informação da Iberoamérica e Caribe (EDICIC), evento ocorrido em 2016, na cidade de Belo Horizonte.
} 